Bond University

Research Repository

\title{
Gambling on gambling
}

\section{Financial implications of raising bet limits and table differentials}

Spence, Mark T.; Kale, Sudhir H.; Sugden, Stephen

Published in:

Journal of Gambling Business \& Economics

Link to output in Bond University research repository.

Recommended citation(APA):

Spence, M. T., Kale, S. H., \& Sugden, S. (2013). Gambling on gambling: Financial implications of raising bet limits and table differentials . Journal of Gambling Business \& Economics, 7(1), 55-72.

\footnotetext{
General rights

Copyright and moral rights for the publications made accessible in the public portal are retained by the authors and/or other copyright owners and it is a condition of accessing publications that users recognise and abide by the legal requirements associated with these rights.
}

For more information, or if you believe that this document breaches copyright, please contact the Bond University research repository coordinator. 


\section{GAMBLING ON GAMBLING: FINANCIAL IMPLICATIONS OF RAISING BET LIMITS AND TABLE DIFFERENTIALS}

Mark T. Spence ${ }^{\mathrm{a}}$, Sudhir H. Kale ${ }^{\mathrm{a}}$, Stephen Sugden ${ }^{\mathrm{b}}$

${ }^{a}$ Faculty of Business, Bond University, Gold Coast, QLD 4229, Australia

${ }^{\mathrm{b}}$ School of Mathematical Sciences, Queensland University of Technology, Gardens Point, 2 George Street, Brisbane, QLD 4000, Australia

Corresponding author:

Mark T. Spence

Faculty of Business

Bond University, Gold Coast, QLD 4229, Australia

Email: mspence@,bond.edu.au

Tel: + 61-448857052

Running title: Financial implications of raising bet limits and table differentials 


\title{
GAMBLING ON GAMBLING: FINANCIAL IMPLICATIONS OF RAISING BET LIMITS AND TABLE DIFFERENTIALS
}

\begin{abstract}
The house advantage for Baccarat is known, hence the theoretical win can be determined. What is impractical to theoretically determine is the frequency and financial implications of extreme events, for example, prolonged winning streaks coupled with various betting patterns. The simulation herein provides such granularity. We explore the effect of following the 'hot hand', that is, rapidly escalating bets when players are on a winning streak. To minimize their exposure, casino management sets a table bet maximum as well as a table differential. These figures can and do serve as a means to differentiate one casino from another. As the allowable bet maximum increases so does the total amount bet, which increases the theoretical winnings, thus suggesting that a high bet limit and differential is beneficial for the house. However, the greater are these amounts, the greater the number of shoes that end with players losing relative to a constant betting scenario (the number of times a player wins at all can drop from $\sim 47 \%$ of the time to less than a quarter); but there will, on occasion, be more extreme payouts to players. This simulation is therefore intended to help casino managers set betting limits that maximize total winnings while bearing in mind both the likelihood and magnitude of negative outcomes to the casino.
\end{abstract}

Keywords: casino management, casino marketing, Baccarat, risk exposure, simulation

\section{INTRODUCTION}

Gamblers have endeavoured to develop strategies to "beat the house" for centuries. A means to do so is by using betting strategies, such as the Martingale system that appeared in France in the $1700 \mathrm{~s}$. When following this strategy, bettors double their bet each time they lose. Regardless of how long a series of losses persists, inevitably a win will occur, thus recovering all prior losses as well as returning a small profit equivalent to the initial bet size. Thus, in theory the Martingale system has a positive expected value. Unfortunately for bettors, theory does not match reality for two reasons: (1) bettors do not have unlimited funds, thus precluding the ability to constantly double their bets should there be a prolonged string of losses; and, (2) gaming establishments set bet maximums. While billionaires may consider the first constraint irrelevant, the latter guarantees that players will periodically incur large losses, thus ensuring profits for the gaming establishment (Hannum and Cabot, 2001). Nevertheless, the use of betting strategies persists (Gainsbury, et al., 2012).

The aforementioned strategy along with others such as the Fibonacci involves escalating bet amounts following losses. However, on both theoretical (Alter and Oppenheimer, 2006; Langer, 1975) and empirical grounds (Chau and Phillips, 1995; Croson and Sundali, 2005; Lam, 2007, Keren and Wagenaar, 1985) there is evidence of an alternative strategy: escalating bets when one is on a winning streak or "hot hand". Following the hot hand is particularly prevalent among Chinese gamblers (Chau and Phillips, 1995; Lam, 2007), although findings from North America (Croson and Sundali, 2005) and Europe (Keren and Wagenaar, 1985) also provide corroborating evidence. But bet maximums are still in place, which limits the house's risk exposure in the event of a prolonged winning streak. However, setting the bet maximum too low can be unappealing for bettors, whereas setting the maximum allowable bet too high could be financially ruinous. The ratio of the maximum bet to the minimum bet, referred to as the multiple or differential, in conjunction with the maximum allowable bet therefore can and does serve as a means to differentiate one casino from another. However, setting these limits seems to be driven by competitive matching, rather than a conclusion derived from a rigorous mathematical exercise.

Matching the competition is not unusual. Empirical evidence regarding slot-hold percentages indicates this is the case (Schwartz, 2013). Consumers are savvy at identifying establishments that 
offer the most advantageous betting environment within their jurisdiction, hence leading to a convergence in slot-hold percentages (Schwartz, 2013). Although we are unaware of published data regarding posted table maximums and table differentials, our experience in the industry suggests that casino executives are keenly aware of what neighbouring casinos are doing in regards to betting limits.

This manuscript takes the position of the gaming establishment and, using a Baccarat game simulation, addresses the following questions:

1) What multiple and maximum bet size can the gaming establishment support, that is, can the individual payout(s) be made?

And the obverse of that question:

2) Given the risk exposure deemed acceptable in response to the first question, how much will the establishment expect to make in return?

The focus herein is Baccarat, a hugely popular game amongst Chinese gamblers in Macau. Gambling revenues in Macau exceeded USD\$33 billion in 2011(UNLV Center for Gaming Research). Of that amount, $73 \%$ came from VIP Baccarat, which is played by an audience that would shun establishments with low table maximums. The odds of winning in Baccarat are known and there is no means by which players can affect those odds. Thus, the higher the allowable betting limit, the greater the theoretical win for the house, determined by the house advantage times the amount wagered. But winning streaks can and do happen, hence there have been multimillion dollar payouts. In one much publicized case a player had combined winnings of over $\$ 15$ million from three establishments (nearly $\$ 6$ million of that from one casino in one night), severely impacting the profit margins of all three and causing at least one casino executive to be fired (The Atlantic, 2012). Thus, answering the two questions presented above has clear practical import, both financially as well as strategically (i.e., ensuring adequate cashflow and differentiating a gaming establishment from its competitors).

To answer these questions, this manuscript is organized as follows. First, we review the psychological evidence for why people follow streaks as well as share existing empirical support for the prevalence of doing so. Second, the rules of Baccarat are briefly reviewed. Third, we elucidate the assumptions of the gaming simulation developed to answer the two questions posed above. Fourth, results are presented from a simulation that represents 30,000 shoes of play, each shoe of which lasts 50 hands. This simulation -1.5 million individual hands of play - therefore represents the approximate amount of play on 15 tables during the course of a month. We conclude with managerial implications.

\section{PSYCHOLOGICAL EXPLANATIONS FOR BETTING STRATEGIES}

Two heuristics that describe betting behaviour have been well documented: the gambler's fallacy and the hot hand fallacy (c.f., Alter and Oppenheimer, 2006; Croson and Sundali, 2005). In both cases subjective probabilities regarding the outcome of random events deviate systematically from objective probabilities. In the case of the gambler's fallacy a string of like outcomes, for example, several tails in a row, alters perceptions regarding the likelihood that another tail will occur on the next trial. In this situation, one's subjective probability for another tail drops below 50\%. Psychologists attribute this to the representativeness bias or "law of small numbers" (Tversky and Kahneman, 1971). Individuals possess preconceived notions of what a pattern of random events should look like; for some, a string of similar outcomes is inconsistent with their expectations. Embracing the gambler's fallacy provides a psychological justification for raising bets following a string of losses or decreasing bets following a string of wins, which has received empirical support. For example, Croson and Sundali (2005) found that in real games of roulette where the focus was on even-money back bets (e.g., Red/Black, Even/Odd) some participants betted against a sequence that had exhibited four consecutive wins (also see Keren and Wagenaar, 1985). However, they also found simultaneous 
evidence for the hot hand fallacy: the number of bets placed increased following a win and decreased following a loss, whether the analysis was on even-money bets or inside bets (choosing specific numbers).

While the gambler's fallacy is predicated on the belief of a negative autocorrelation in random events, the hot hand fallacy assumes positive autocorrelation. Thus, the emergence of a streak raises the subjective probability relative to the objective probability that another similar outcome will occur. The 'illusion of control' is thought to drive beliefs in the hot hand fallacy (Langer, 1975). Mankind has an innate desire to master their environment, or at least to understand the causal mechanisms bringing about effects. It appears that perceiving a hot hand blurs one's ability to differentiate skill from chance and luck (Langer, 1975). Wagenaar and Keren (1988; Keren and Wagenaar, 1985) cogently make this distinction. People seem to understand that chance leads to a fair distribution of outcomes in the long term. However, should a streak of similar outcomes occur, rather than attributing this to chance they look for an alternative cause: luck. Thus, chance and luck are different, but appear to be complementary (Wagenaar and Keren, 1988). In a gambling related survey, Wagenaar and Keren (1988) noticed that subjects were uncomfortable allocating $100 \%$ to skill or chance in determining the outcome to gambles, but this was not the case when a third factor, luck, was introduced. With respect to luck, "people believe one cannot force luck to happen, and in that sense it is much like chance. One should wait until luck appears ... In this sense the utilization of luck is more like a skill" (Wagenaar and Keren, 1988, p. 66). Interestingly, luck was perceived as having the greatest influence on gambling outcomes (45\%), relative to skill (37\%) and chance (18\%). Learning to identify when one is lucky and acting upon that insight therefore creates an illusion of control.

Like Americans, Chinese gamblers believe that luck influences their winnings (Ozorio and Fong, 2004; Lam, 2007). Bet amounts increase noticeably as winning streaks emerge, as does the number of bettors at a given table. "Hoppers" move from table to table placing back bets in an effort to follow winning streaks, and then move tables when a hand is lost (Lam, 2007). Lam (2007) goes on to provide observational insights into how illusion of control is manifested, such as in the ways that Chinese Baccarat players peel or "squeeze" cards, and the words they shout. Squeezing the cards is a means by which players channel their energy into the cards to influence the outcome of the game (Inside Asian Gaming, 2013). Actions such as these, which presumably influence one's luck, are consistent with other studies that have unearthed superstitions that gamblers hold (Joukhouder, et al., 2004). To Chinese, luck is not relegated to gambling, but applies to business as well. Pitta, Fung and Isberg (1999) found that Chinese rated luck as more important to success in business than knowledge.

Numerous gaming related studies have provided further evidence in support of the hot hand fallacy, individuals raising their bets following wins (c.f., Chau and Phillips, 1995; Keren and Wagenaar, 1985; Lam, 2007) or placing more bets following a win (Croson and Sundali, 2005). But this behaviour is not relegated to gaming. For example, Sirri and Tufano (1998) found that consumers make mutual fund purchases based upon the past performance of fund managers. Alter and Oppenheimer (2006) go so far as to describe the existence of the hot hand fallacy as "unassailable".

If a means to know if one is lucky includes the ability to discern a trend - a hot hand - when does this occur? Across five studies Carlson and Shu (2007, p. 113) found support for the rule of three: "the third repeat of an event in a sequence is pivotal to the subjective belief that a streak is occurring". This was true across a variety of domains. Their study 2 specifically dealt with discerning streaks in random events, like flipping coins and tossing dice. Thus, if a run of three signals a streak, for those that embrace the hot hand fallacy bet amounts would increase appreciably following a the third consecutive win.

\section{THE GAME OF BACCARAT}

The rules of Baccarat are well articulated and readily available in casinos and on-line (see for example, www.netbet.org/baccarat/rules.html, accessed Feb 25, 2013). Put simply, Baccarat is typically played from a shoe consisting of 6 or 8 decks. The dealer selects the first card in the shoe, its value of which determines the number of cards in the shoe that are "burned" (removed from play), 
which is a maximum of ten cards. Game play can then commence. Players have three options on which to bet, Player, Banker or Tie, each of which has different house advantages. Bets must be placed prior to the dealing of any cards. Bet size is the only variable available to the player. In this respect, Baccarat bears resemblance to Roulette, Keno or Craps, and is unlike Blackjack where players have to decide whether or not to select a card or cards, which alter the odds of winning. Thus, once bets are placed and the game commences, there is nothing Baccarat players can do to alter the odds of winning.

If you bet on the Player and win, you receive a 1 to 1 payout. A winning bet on the Banker also pays out 1 to 1 , but a $5 \%$ commission must be paid back to the casino. The commission exists because a Banker bet has greater odds of winning relative to a Player bet, although both Player and Banker bets have some of the best odds relative to other common "even money" gambles, like betting odds or evens in Roulette. A Tie bet pays out 8 to 1, but a tie is the least likely of outcomes and has by far the greatest house advantage.

Because Baccarat is played from a shoe without replacement, dealt cards in a given hand are serially dependent upon the prior games play. However, unlike Blackjack where card counting - a means to benefit from serial dependence - can shift the odds to the gambler's advantage, in Baccarat "it is not possible for the player to take advantage of the dependency and baccarat is for all practical purposes a game of pure chance" (Hannum and Cabot, 2001, p. 101).

A Baccarat table typically accommodates 14 players, however betting is not limited to 14 players. In most gaming jurisdictions, back betting in Baccarat is allowed, and is common amongst hoppers that follow winning streaks and stand behind seated players and place bets on the table (Lam, 2007). Casino executives have reported that on hot hand streaks as many as 30 individual bets can be placed, and this figure is constrained only because of physical limitations of getting to the table to place a bet. Technology could be put in place to increase the number of allowable players, if this were deemed advantageous, as could alternative table formats. The Venetian Macao, for example, has rolled out four Fast Action Baccarat tables that can each accommodate up to 60 standing players (Inside Asian Gaming, 2013).

Of critical relevance from a risk exposure perspective is that bets tend to be lopsided in favour of Player or Banker, and this is particularly apparent when a winning streak appears (Lam, 2007). Streaks are readily identified. Not only is it common for tables to have an electronic display board posting the disposition of outcomes from prior hands that includes displaying streak length prior to a switch (from Player to Banker or vice versa), it is also common for individual players to keep track of their own game outcomes on scorecards provided by casinos.

In an online article, "What Causes Streaks in Gambling?", gaming guru Alan Krigman (1997, p. 1) explains, "Baccarat buffs believe in streaks so strongly they keep track of results on little scorecards. The principal bets in this game, "player" and "banker", each win close to half of all decisions. The chance of a run of 10 winning player or banker hands in a row is a modest one out of 512. However, in 500 rounds, the chance of at least one such streak exceeds one out of five. A solid citizen could easily play 500 rounds during a casino visit, and therefore wouldn't find a 10-hand streak unusual. A frequent player would think such phenomena dominate the game, having seen them often."

\section{SIMULATING BACCARAT PLAY}

\subsection{Justification for using a simulation}

Before proceeding, it is important to note that the house advantage in established games like Baccarat are known and fixed, hence the theoretical win can be accurately determined (Hannum and Cabot, 2001). It is also known that non-constant betting strategies will alter the variance and skewness of payouts in the short term (Turner, 1998). What is impractical to theoretically determine is the 
frequency and corresponding financial implications of extreme events, for example, various combinations of winning streaks coupled with various betting patterns. The simulation herein provides such granularity (for a simulation of Kelly betting, see Buchen and Grant, 2012). Although the focus is on Baccarat, this simulation can be modified to correspond to other games that have no more than three possible outcomes (e.g., Blackjack).

\subsection{Underlying parameters within the simulation}

Given the two research questions raised in the introduction, the focus is on unearthing the implications of all bets being placed on either Player or Banker. However, this assumption can be relaxed if one prefers to think of the net difference between Player and Banker bets. Thus, without loss of generality we can think of the table as having one player. The player initially decides to bet on either Player or Banker, and starts gambling with a bet of $\$ 100$. Possible outcomes are Banker win, Player win or Tie, denoted B, P, and T, respectively. A shoe is assumed to last 50 hands. We simulate 30,000 shoes of play, or 1.5 million hands of play. Relevant symbols and values within the simulation appear in Table 1.

\section{Table1. Simulation symbols and values}

\begin{tabular}{|c|l|l|}
\hline Symbol & Meaning & Value \\
\hline$n_{\max }$ & maximum number of games in a shoe & 50 \\
\hline$n$ & game number & $1 \leq \mathrm{n} \leq \mathrm{n}_{\max }$ \\
\hline$p$ & probability of Player win in 1 game & 0.44625 \\
\hline$b$ & probability of Banker win in 1 game & 0.45860 \\
\hline$t$ & probability of Tie in 1 game & 0.09515 \\
\hline$z_{n}$ & outcome on game $n$ & $\{P, B, T\}$ \\
\hline
\end{tabular}

\subsection{Defining a run and its length: $L_{n}$}

A run or streak may consist of a series of Player wins or Banker wins. A Player run is defined as any contiguous sequence of outcomes beginning with a Player win and containing no Banker win. Thus, ties may appear anywhere in a Player run, but may not begin it. A run may be terminated by either a win for the Banker or by the last game in the shoe, set at 50 . We define the length of a Player run to be simply the number of Player wins in the streak. Examples of Player runs are shown in Table 2 .

Table 2. Examples of Player runs

\begin{tabular}{|l|l|l|l|l|l|l|l|l|l|l|l|}
\hline Game \# n & 41 & 42 & 43 & 44 & 45 & 46 & 47 & 48 & 49 & 50 & $\begin{array}{l}L_{n} \\
\text { Run } \\
\text { Length }\end{array}$ \\
\hline Ex. 1 & P & P & P & P & P & B & & & & & 5 \\
\hline Ex. 2 & P & T & T & P & P & P & B & & & & 4 \\
\hline Ex. 3 & P & T & T & T & B & & & & & & 1 \\
\hline Ex. 4 & B & P & P & T & P & P & P & P & T & P & 7 \\
\hline
\end{tabular}

Banker runs are the obverse of the above and are encoded as negative for modelling purposes.

For the first game in the shoe, $n=1$, we have: 


$$
L_{1}=\left\{\begin{array}{ccc}
1 & \text { if } & z_{1}=P \\
-1 & \text { if } & Z_{1}=B \\
0 & \text { if } & z_{1}=T
\end{array}\right.
$$

For subsequent games, $L_{n}$ is:

\begin{tabular}{|l|l|l|l|}
\hline & \multicolumn{3}{|c|}{ Outcome for game $Z_{n}$} \\
\hline $\begin{array}{l}\text { Previous run length, } \\
\text { denoted } L_{n-1}\end{array}$ & $\mathrm{~B}$ & $\mathrm{~T}$ & $\mathrm{P}$ \\
\hline$<0$ & $L_{n-1}-1$ & $L_{n-1}$ & 1 \\
\hline 0 & -1 & 0 & 1 \\
\hline$>0$ & -1 & $L_{n-1}$ & $L_{n-1}+1$ \\
\hline
\end{tabular}

\subsection{The run follower}

The focus herein is on the financial implications of bettors that follow streaks, whether they are Player runs or Banker runs, and call him the run follower (RF). RF bets on $R_{n}$ in game $n$ and this behaviour is simulated as follows. On the first game he bets on Player or Banker with probability 0.5 each. Thereafter, he bets on the same outcome (P or B) as he did on the previous game unless there is a run of length two on the "other side", in which cases he switches to that side. RF will stay on the side of a run if current run length is two or more, and stay on the side of the run even if the run breaks. He will only switch allegiance if a run of length two becomes evident "on the other side". These behavioural assumptions are based on actual observations of Baccarat players in Macau.

\subsection{Betting index: $x_{n}$}

The betting index determines what amount in a sequence of escalating bets is to be placed on the current hand by RF, based on RF's previous bet, previous outcome and current run length. We start with $x_{1}=1$, and thereafter for $n \geq 2, x_{\mathrm{n}}$ is defined as:

\begin{tabular}{|c|c|c|}
\hline & \multicolumn{2}{|c|}{ Bet by run follower on game $n-1$} \\
\hline$L_{n-1}$ & B & $\mathrm{P}$ \\
\hline$-1,0,1$ & $\begin{array}{l}\text { If } Z_{n-1}=P \text { then } x_{n}=1 \\
\text { If } Z_{n-1}=T \text { then } x_{n}=x_{n-1} \\
\text { If } Z_{n-1}=B \text { then } \\
x_{n}=x_{n-1}+1\end{array}$ & $\begin{array}{l}\text { If } z_{n-1}=B \text { then } x_{n}=1 \\
\text { If } z_{n-1}=T \text { then } x_{n}=x_{n-1} \\
\text { If } z_{n-1}=P \text { then } \\
x_{n}=x_{n-1}+1\end{array}$ \\
\hline$\geq 2$ & $x_{n}=1$ & $\begin{array}{l}\text { If } z_{n-1}=T \text { then } x_{n}=x_{n-1} \\
\text { else } x_{n}=x_{n-1}+1\end{array}$ \\
\hline$\leq-2$ & 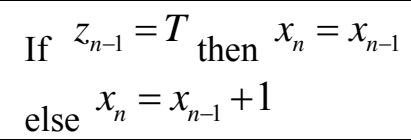 & $x_{n}=1$ \\
\hline
\end{tabular}


Thus, the betting index can range from 1 to 50 , the latter occurring in the unlikely event of 50 consecutive Player wins or Banker wins, with no intervening ties.

\subsection{Betting strategies}

The purpose of this simulation is to assess the effect of various betting strategies on the house from both a profitability and risk standpoint. Five betting strategies and corresponding bet amounts are analysed and appear in Table 3. The five betting strategies considered are: constant, linear, an actual betting pattern observed in a large Macau casino with the maximum bet capped at 30 times the minimum (denoted Actuals in Table 3), plus two more extreme betting strategies that mimic the Actuals S-shaped bet pattern provided, labelled Extreme1 and Extreme2. Consistent with Carlson and Shu's (2007) 'rule of three', note that for Actuals the bet amounts escalate exponentially after three consecutive wins, reaching an inflection point after a run of six. With the exception of constant betting (the same amount is wagered on each hand regardless of prior wins or losses), each of the betting strategies assumes the bet amount will stay the same or increase following a win and will return to the initial bet amount $(\$ 100)$ following a loss. However, the simulation can be programmed to accommodate any desired betting patterns. How much is bet following a win is determined by the betting index. The longer the winning streak, the greater the amount bet, except in the case of Constant bettor.

In Table 3 the Actuals (recalibrated data gathered from a casino so that the starting bet is $\$ 100$ ) has a multiple of 30; thus, the maximum bet is 30 times the starting position. Extreme1 reflects a multiple of 100, which is being trialled by some casinos in Macau. Extreme2 is a hypothetical stretch: what would happen if the multiple were 1000? Technology exists to allow sufficient back bets to realize this outcome, if casino management so desired. Note that these three betting strategies increase in a curvilinear fashion, rapidly escalating after the third win, but reaching a limit after a streak of 10 consecutive wins, after which the bet amount stays the same regardless of run length, which in theory could be 50 consecutive wins. For the linear bet the gambler increases their bet amount by $\$ 100$ following a win, and continues doing so as long as the streak continues.

Table 3: Bet amounts as a function of length of winning streak (determined by the betting index)

\begin{tabular}{|lr|r|r|r|r|r|}
\hline \multicolumn{2}{|l|}{ betting } & & & & & \\
& 1 & Actuals & Extreme1 & Extreme2 & Linear & Constant \\
& 1 & $\$ 100$ & $\$ 100$ & $\$ 100$ & $\$ 100$ & $\$ 100$ \\
& 100 & 100 & 100 & 200 & 100 \\
& 133 & 443 & 1200 & 300 & 100 \\
& 3 & 315 & 1050 & 10500 & 400 & 100 \\
& 728 & 2427 & 24267 & 500 & 100 \\
& 5 & 1064 & 3547 & 35467 & 600 & 100 \\
6 & 1596 & 5320 & 53200 & 700 & 100 \\
7 & 2183 & 7277 & 72767 & 800 & 100 \\
8 & 2911 & 9703 & 97033 & 900 & 100 \\
9 & 3000 & 10000 & 100000 & 1000 & 100 \\
10 & 3000 & 10000 & 100000 & 1100 & 100 \\
\hline 11 & & \multicolumn{3}{|c}{} \\
\hline
\end{tabular}

\section{THE SIMULATION RESULTS}

\subsection{Verification checks}


Simulations, by their nature, will yield variations in outcomes as would any snapshot of realworld game play. What is reported below is the result of simulating 30,000 shoes of action, with each shoe lasting 50 hands. Thus, the simulation represents 1.5 million hands of play, roughly the amount of play that might be realized on 15 tables during the course of a month. Two critical parameters are that the simulated win/loss frequencies are consistent with expected win percentages, and that the overall house advantage is in accord with expectations. Table 4 shows the win frequencies within the simulation compared to the expected frequencies. For Player and Banker outcomes, the discrepancy is less than $0.01 \%$.

Table 4. Win frequencies within the simulation versus expectations

\begin{tabular}{|l|r|r|r|}
\hline & Player & Banker & Tie \\
\hline $\begin{array}{l}\text { Simulation } \\
\text { frequencies }\end{array}$ & 0.446292 & 0.458599 & 0.095109 \\
\hline Expected frequencies & 0.446250 & 0.458600 & 0.095150 \\
\hline
\end{tabular}

Table 5 shows the results after 30,000 shoes. For the Constant bettor that bets $\$ 100$ per hand, the total amount wagered after 1.5 million hands, referred to as the player contribution or the 'handle', would be $\$ 150,000,000$, as shown. The 'Return to House \%' can be thought of as the realized house advantage: it is the total amount lost by the player divided by the handle. The true house advantage for a Player bet is $1.24 \%$, for a Banker bet is $1.06 \%$, and $14.36 \%$ for a Tie, thus leading to an overall house advantage of $1.15 \%$ (Hannum and Cabot, 2001). In this simulation, for the Constant better the house realized a return of $1.058 \%$. This figure is well within a $95 \%$ confidence interval for casinos that are willing to be within $0.15 \%$ of the theoretical win after 1.5 million hands (Hannum and Cabot, 2011).

Table 5. Outcome experienced by the bettor after 30,000 shoes

\begin{tabular}{|l|c|c|c|c|c|}
\hline & Constant & Linear & Actuals & Extreme1 & Extreme2 \\
\hline $\begin{array}{l}\text { Prize money (amount } \\
\text { lost by player, \$) }\end{array}$ & $-1,587,370$ & $-3,045,755$ & $-2,901,008$ & $-6,693,614$ & $-50,996,036$ \\
\hline Player Contribution (\$) & $150,000,000$ & $293,756,900$ & $264,054,128$ & $614,046,955$ & $4,521,359,306$ \\
\hline Return to House \% & $1.058 \%$ & $1.037 \%$ & $1.099 \%$ & $1.090 \%$ & $1.128 \%$ \\
\hline $\begin{array}{l}\text { Min shoe revenue } \\
\text { (greatest loss by layer, \$) }\end{array}$ & $-2,635$ & $-3,535$ & $-2,635$ & $-5,334$ & $-77,278$ \\
\hline $\begin{array}{l}\text { Max shoe revenue } \\
\text { greatest win by player, } \\
\text { \$) }\end{array}$ & 2,460 & 17,010 & 36,446 & 121,346 & $1,213,072$ \\
\hline Median win/-loss (\$) & -55 & -375 & -655 & $-2,397$ & $-18,496$ \\
\hline Mean win/-loss (\$) & -52.9 & -101.5 & -96.7 & -223.1 & $-1,699.9$ \\
\hline Std. deviation & 664 & 1559 & 2120 & 6813 & 67212 \\
\hline Skewness & 0.02 & 1.37 & 4.55 & 4.93 & 4.95 \\
\hline Kurtosis & -0.10 & 4.00 & 31.73 & 35.62 & 36.48 \\
\hline
\end{tabular}

The summary statistics in Table 5 show that a constant bettor will realize a normal distribution in outcomes with a mean loss of $\sim \$ 53$ for one shoe of play. Note that all the escalating betting strategies result in a great player contribution and ultimately more money being lost by the player, as would be expected given that Baccarat has negative expected returns. It should be assumed 
that "in the long term" the return to player percentages would converge on the house advantage regardless of betting strategy (Hannum and Cabot, 2001).

Consistent with Turner (1998), non-constant monotonic betting strategies affect the skewness of the payouts. In this case there is a right skew, and the skewness increases as the multiple increases. To make just two comparisons, for the Actuals betting pattern the mean loss is $\sim \$ 97$ per shoe. The greatest loss experienced by the player across all the shoes is $\$ 2635$, coincidentally equal to the constant better; however, the greatest win would be $\$ 36,446$, about 15 times more than the constant better - an outcome clearly appealing to those that crave skewness and the lure of a large win (Golec and Tamarkin, 1998). What is important to note from a risk exposure standpoint is how the shoe revenues change as the multiple increases from 30 (Actuals), to 100 (Extreme1) to 1000 (Extreme2). For Extreme3, the worst loss for a shoe experienced by the player would be $\$ 77,278$; however, in one of the shoes the player would have received a payout of $\$ 1,213,072$. The mean loss increases as bets are allowed to escalate resulting in greater profits overall for the house reflected in the 'prize money', but so does the likelihood and the amount of extreme payouts to players that the casino must be prepared to make. Figure 1 sheds insight into the cumulative frequency of outcomes, although for scale reasons Extreme 2 is omitted and the right tail is cut-off at payouts to players equal to $\$ 10,000$, which only affects Extreme1. What is apparent is the normality of the constant bettor's payouts, and that the escalating betting patterns cause mean payouts to shift left and for the player to experience a greater number of losing shoes than would be the case had they used a constant betting strategy. To elucidate on the implication of the skewness in payouts - hence risk exposure for the gaming establishment - if we consider just the extreme right hand $1 \%$ of shoes (the farthest right 300 shoes, which would all involve wins for the player and in the case of Extreme1 would be far to the right of what appears in Figure 1), the range of payouts from the casino to the player would be:

\section{9\% cut-off $\quad$ Greatest payout}

$\begin{array}{llll}\text { Constant: } & \$ 1,480 & \rightarrow & \$ 2,460 \\ \text { Linear: } & \$ 4,940 & \rightarrow & \$ 17,010 \\ \text { Actuals: } & \$ 9,892 & \rightarrow & \$ 36,446 \\ \text { Extreme1: } & \$ 33,578 & \rightarrow & \$ 121,346 \\ \text { Extreme2: } & \$ 329,083 \rightarrow & \$ 1,213,072\end{array}$

In the case of Extreme2, this would result in total payouts for these 300 shoes of $\$ 134,496,925$ (the payouts for individual shoes lies within the range above). Given that overall an escalating betting strategy is advantageous to the house as shown in Table 5, if these "bad shoes" were distributed throughout the 30,000 shoes it could be argued that these extreme payouts pose little threat to the establishment. But randomness is clumpy (Turner, 1998). A series of high payout shoes to players in relatively short order could have deleterious consequences, conceivably bankrupting an establishment. At a minimum it would impact profits, which may in turn damage the stock price; likely raise issues regarding the possibility of a security breach; possibly lead to dismissals; and/or draw media attention (The Atlantic, 2012). 
Figure1. Frequency distribution of player losses and wins (right skew truncated at $\mathbf{\$ 1 0 , 0 0 0}$ )

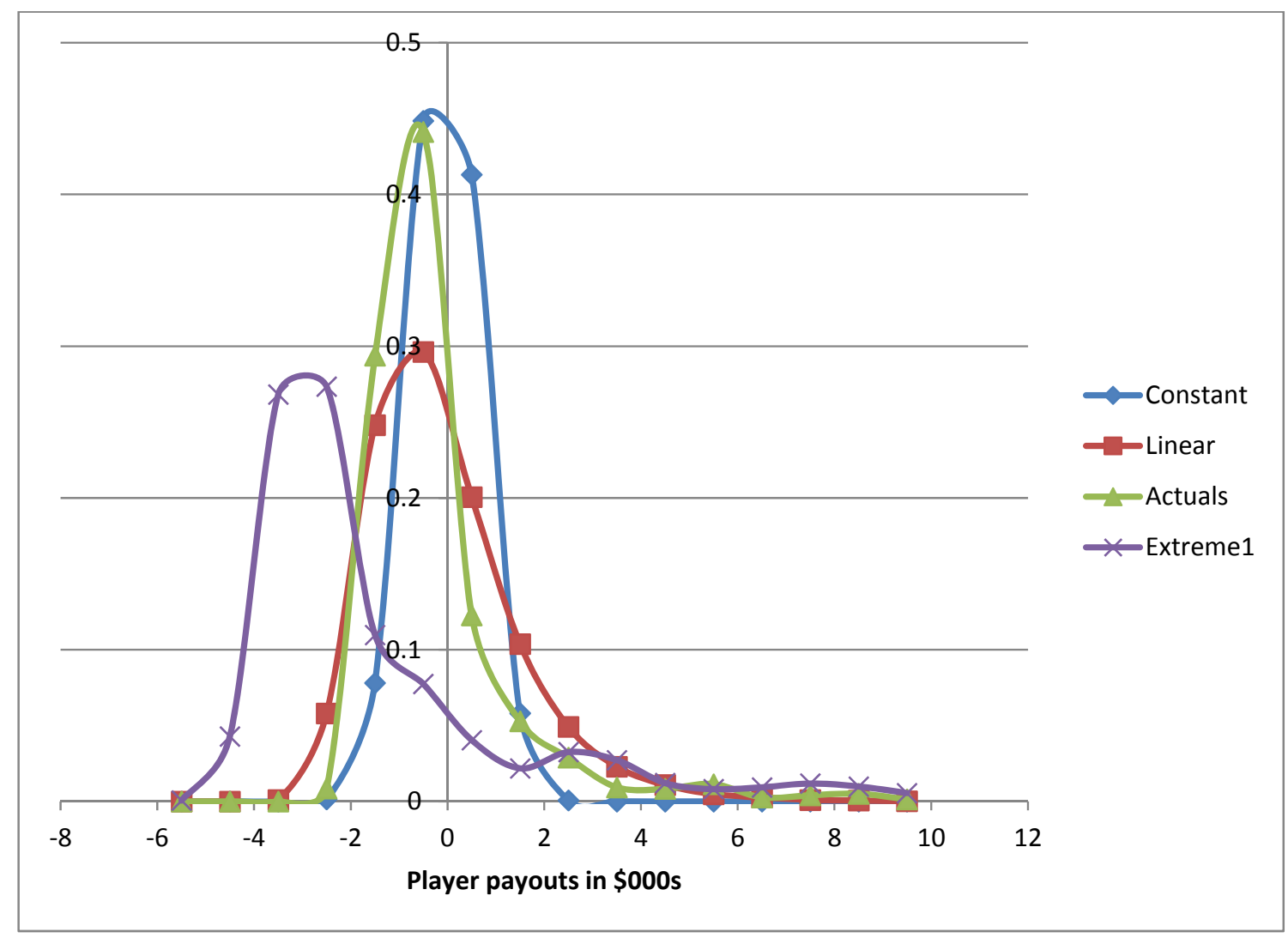

While the focus thus far has been on the financial implications to the casino establishment, what have been ignored thus far are possible ramifications of the different betting strategies. In most cases betting strategies do not affect whether a player wins or loses in a given shoe, but they do affect the amount that the player wins or loses. But that is not always the case. Betting patterns can cause a losing shoe to flip to a winning shoe relative to constant betting, or vice versa. Table 6 reveals how different betting patterns affect win/loss outcomes by individual shoes of play. In the left four columns are the numbers of times that the escalating betting patterns returned a positive amount to the player whereas the constant betting pattern returned a loss. The right four columns show the reverse. Given the right skew (refer to Figure 1), it should not be surprising that the constant betting pattern is more likely to result in a winning shoe for the player relative to the other betting behaviours. Indeed, for all three S-shaped bet escalation strategies, in over $25 \%$ of the shoes the player would have actually won money had they used a constant betting strategy instead of escalating bets in response to perceived streaks (right four columns). Conversely, depending on betting strategy, between $3.6 \%$ and $6.5 \%$ of the time players would have made money - and possibly a lot of it - by escalating their bets whereas the constant betting pattern resulted in a loss. For many bettors it is the possibility of extreme wins that is the attraction to gambling (Golec and Tamarkin, 1998), hence the preponderance of losses given an escalating betting strategy is an outcome some individuals would willingly take. But if the number of wins becomes too infrequent, it seems reasonable to assume that some people would conclude they are on a losing streak and cease playing, in which case neither the handle nor the theoretical win shown in the simulation would be realized. Out of 30,000 shoes, constant betting resulted in 14,158 wins ( $47.2 \%$ of the time, including break evens), whereas this figure dropped to 7,694 wins (25.6\%) for Actuals and 6,868 wins (22.9\%) for Extreme2. Thus, the downside of 
pursuing a strategy with the hopes of winning big is to drop the likelihood of winning at all by about half. For those that do not win big, this could certainly be frustrating.

Table 6. Number of times betting strategies cause a reversal in winnings

\begin{tabular}{|c|c|c|c|c|c|c|c|c|}
\hline \multicolumn{5}{|c|}{$\begin{array}{l}\text { Non-constant betting is better } \\
\text { than constant betting }\end{array}$} & \multicolumn{4}{|c|}{ Constant is better } \\
\hline & 莺 & $\begin{array}{l}\frac{n}{\pi} \\
\frac{\vec{Z}}{2} \\
\frac{\pi}{4}\end{array}$ & 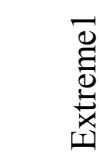 & 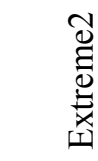 & 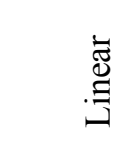 & $\begin{array}{l}\frac{n}{\widetilde{J}} \\
\vec{Z} \\
\mathbb{U}\end{array}$ & 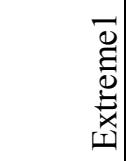 & 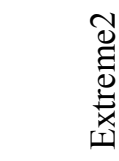 \\
\hline Frequency & 1528 & 1093 & 1525 & 1957 & 3768 & 7529 & 8818 & 9217 \\
\hline Percent & $5.1 \%$ & $3.6 \%$ & $5.1 \%$ & $6.5 \%$ & $12.6 \%$ & $25.1 \%$ & $29.4 \%$ & $30.7 \%$ \\
\hline
\end{tabular}

\section{DISCUSSION}

"The long run is a misleading guide to current affairs. In the long run we are all dead." John Maynard Keynes

The growth in both gambling revenues and patron numbers in Macau and other Asian jurisdictions such as Singapore has been seemingly impervious to the recent global financial crisis. Nevertheless, it would be perilous to assume that the good times will continue unabated and that a build-it-and-they-will-come strategy is financially wise. Thus, it is imperative for gaming establishments to do what they can to differentiate themselves from their competitors and endeavour to cultivate relationships with their customers. Building ever grander gaming environments and offering generous terms and conditions to high rollers (such as altering the rules of play, and/or providing dead chips and loss rebates) are means by which casinos compete for players. Another means to entice visitors is to broaden the non-gaming revenue by offering showroom entertainment, although this appears to have negligible knock-on effects on gaming revenue (Suh, 2011). Herein, the focus is on the implication of using the table differential and the table bet maximum as means to differentiate a casino from its competitors. The simulation presented in this article sheds light on the financial implications of varying these numbers when combined with various betting strategies.

Most Baccarat players believe in and follow streaks, and raise their bets when they are on a hot hand (Croson and Sundali, 2005; Krigman, 1997; Wagenaar and Keren, 1988). A run of three signals the emergence of a streak (Carlson and Shu, 2007). Any bet pattern that is monotonic and only applies in one direction (consistently raising bets after a win if following the hot hand as analysed herein, or, conversely, raising bets after losses if embracing a strategy such as the Martingale) will alter the variance and skewness of payouts in the short term. Raising bets when on a winning streak creates a right skew. The net result is that escalating betting strategies result in greater overall losses for bettors and greater average losses by shoe, and both these figures increase as the differential and table bet maximum increase. But escalating bets does provide the opportunity for much larger wins, which does appeal to bettors that crave skewness in outcomes over mean returns (Cowley, 2013; Golec and Tamarkin, 1998). As Golec and Tamarkin (1998, p. 221) cogently state: "the possibility of a large win is what lures them". To win big in even money bets, like betting on Player in Baccarat, one must bet beg.

If one follows the Martingale system at a casino that offers a generous upper limit, one will go home a winner more often than will be case than if they bet a constant amount; but they will occasionally go home having suffered big losses. Gamblers that have sought clinical assistance have acknowledged this pattern of outcomes (Turner, 1998). Raising bets when on the hot hand has the opposite effect: The gambler will go home a loser far more often than would be the case if they placed constant bets, but will on occasion win - and potentially win big. In the most extreme scenario with a 
table differential of 1000 , one shoe had a payout to the player of over $\$ 1.2$ million, and a projected collective payout for the 300 highest payout shoes for the player (1\% of the total number of shoes simulated) of over $\$ 134$ million, a figure that if realized in a short period of time would be ruinous to a typical casino. If the multiple were instead set at 100, the collective loss for the worst 300 shoes would be $\$ 13,561,429$. Considering it is unlikely that these shoes would happen in rapid succession, this collective loss is one that many casinos would be willing to risk.

But large potential winnings for players come at a cost. If a gambler embraced any of the three S-shaped escalating bet strategies they will go home a winner only about a quarter of the time, whereas with the constant betting strategy they would leave the gaming establishment a winner $\sim 47 \%$ of the time. What cannot be answered is whether the positive emotions stemming from the potential for a large win - an outcome most individuals will rarely if ever realize - will offset the roughly three quarters of the time they go home a loser, which has associated feelings. In the slot machine domain, gaming establishments alter the volatility of payouts to differentiate their establishment from competitors as well as alter the volatility of machines by denomination (e.g., \$.01 machines versus $\$ 1$ ). Because any outcome can happen in the short term, it is common for high volatility machines to have higher hold percentages (Schwartz, 2013). The slot-hold percentage is the "price" gamblers pay to play, and even though the hold percentages may not be posted customers appear to be able to intuit which casino offers the best returns, hence slot-hold percentages converge within a jurisdiction (Schwartz, 2013). Conversations with casino executives in Macau point toward a similar competitive parity strategy with respect to setting the differential and table bet maximum. But the table differential and bet maximum are clearly posted; and it would certainly be feasible to forewarn patrons about the implications (both positive and negative) about different betting strategies, although the authors are not aware of any attempts to do so. We suggest that the frequency and potential magnitude of wins as a function of betting strategy be made available to patrons so that they can make an informed volatility versus expected return trade-off. Casinos can then broaden their appeal by offering the greatest differential and bet maximum that they are capable of financially supporting. A differential of 1000 would be risky for all but the largest of firms; but a differential of 100 and/or a table maximum of $\$ 10,000$ do not appear unreasonable. In sum, this simulation has applications for casino managers desirous of setting their betting limits in an informed manner to maximize wins while bearing in mind the frequency and magnitude of negative outcomes of increased differentials. 


\section{REFERENCES}

Alter, Adam L. and Oppenheimer, Daniel (2006), 'From a fixation on sports to an exploration of mechanism: The past, present, and future of hot hand research', Thinking \& Reasoning, 12(4), 431444.

Buchen, Peter W. and Grant, Andrew (2012), 'A comparison of simultaneous Kelly betting strategies', The Journal of Gambling Business and Economics, 6(2), 1-28.

Carlson, Kurt A. and Shu, Suzanne B. (2007), 'The rule of three: How the third event signals the emergence of a streak', Organizational Behaviour and Human Decision Processes, 104, 113-121.

Chau, Albert W. and Phillips, James G. (1995), 'Effects of perceived control upon wagering and attributions in computer blackjack', The Journal of General Psychology, 122(3), 253-269.

Cowley, Elizabeth (2013), 'Forgetting the anxiety: Gambler's reactions to outcome uncertainty', Journal of Business Research (in press).

Croson, Rachael and Sundali, James (2005), 'The gambler's fallacy and the hot hand: Empirical data from casinos', The Journal of Risk and Uncertainty, 30(3), 195-209.

Gainsbury, Sally, Sadeque, S., Mizerski, D, and Blaszczynski, A. (2012), 'Wagering in Australia: A retrospective behavioural analysis of betting patterns based on player account data', The Journal of Gambling Business and Economics, 6(2), 50-68.

Golec, Joseph and Tamarkin, Maurry (1998), 'Bettors love skewness, not risk, at the horse track', Journal of Political Economy, 106(1), 205-225.

Hannum, Robert C. and Cabot, Anthony N. (2001), Practical Casino Math, Thomas-Shore, Inc., Dexter, MI.

Inside Asian Gaming (2013), 'Built for speed', January, 26-29.

Joukhador, Jackie, Blaszczynki, Alex and MacCallum, Fiona (2004), 'Superstitious beliefs in gambling among problem and non-problem gamblers: preliminary data', Journal of Gambling Studies, 20(2), 171-180.

Keren, Gideon and Wagenaar, William A. (1985), 'On the psychology of playing blackjack: Normative and descriptive considerations with implications for decision theory', Journal of Experimental Psychology: General, 114(2), June, 133-158.

Krigman, Al (1997), 'What causes streaks in gambling?', Casino City Times. Accessed online Feb 28, 2013: http://krigman.casinocitytimes.com/article/what-causes-streaks-in-gambling-5341

Lam, Desmond (2007), 'An observation study of Chinese baccarat players', UNLV Gaming Research \& Review Journal, 11(2), 63-73.

Langer, Ellen J. (1975), 'The illusion of control', Journal of Personality and Social Psychology, 32(2), 311-328.

Ozorio, B. and Fong, D.K.C. (2004), 'Chinese casino gambling behaviours: Risk taking in casinos versus investment', UNLV Gaming Research \& Review Journal, 8, 27-38.

Pitta, D.A., Fung, H.G. and Isberg, S. (1999), 'Ethical issues across cultures: Managing the differing perspectives of China and the USA', Journal of Consumer Marketing, 240-256.

Schwartz, David G. (2013), 'Penny wise, player foolish? Slot-hold regulation and consumer preference', Journal of Business Research (in press). 
Sirri, Erik and Tufano, Peter (1998), 'Costly search and mutual fund flows', Journal of Finance, 53, 1589-1622.

Suh, Eunju (2011), 'Examining the indirect impact of showroom entertainment on hourly slot gaming volume: The case of Las Vegas hotel-casino', International Journal of Hospitality Management, 30, 522-529.

The Atlantic (2012), 'The man who broke Atlantic City'. Accessed online Feb 7, 2013:

http://www.theatlantic.com/magazine/archive/2012/04/the-man-who-broke-atlantic-city/308900/

Turner, Nigel E. (1998), 'Doubling vs. constant bets as strategies in gambling', Journal of Gambling Studies, 14(4), Winter, 413-429.

Tversky, Amos and Kahneman, Daniel (1971), 'Belief in the law of small numbers', Psychological Bulletin, 76, 105-110.

UNLV Center for Gaming Research (2013), Macau gaming summary. Accessed online Feb 25, 2013: http://gaming.unlv.edu/abstract/macau.html

Wagenaar, Willem A. and Keren, Gideon B. (1988), 'Chance and luck are not the same', Journal of Behavioral Decision Making, 1, 65-75. 